\title{
Silver Particle Carbon-Matrix Composites as Thick Films for Electrical Applications
}

\author{
YUAN-CHAN HSU, ${ }^{1}$ and D.D.L. CHUNG $^{1,2}$ \\ 1.-Composite Materials Research Laboratory, University at Buffalo, State University of New \\ York, Buffalo, NY 14260-4400, USA. 2.—e-mail: ddlchung@buffalo.edu
}

\begin{abstract}
Silver particle $(3 \mu \mathrm{m})$ carbon-matrix composites in the form of thick films (around $100 \mu \mathrm{m}$ thick) on alumina, as prepared from pastes comprising silver and mesophase pitch particles $(14 \mu \mathrm{m})$, have been attained. The films on alumina were fired at $650^{\circ} \mathrm{C}$ in nitrogen to convert pitch to carbon. The volume electrical resistivity attained ranged from $10^{-5} \Omega \mathrm{cm}$ to $10^{4} \Omega \mathrm{cm}$, depending on the silver volume fraction. The percolation threshold was 12 vol\% silver.
\end{abstract}

Key words: Composite, carbon, silver, thick film, electrical resistivity

\section{INTRODUCTION}

Electrically conductive materials in the form of thick films (i.e., coatings of thickness typically of the order of $10 \mu \mathrm{m}$ ) instead of wire or other monolithic forms are attractive for their relatively small size and consequent suitability for device miniaturization. Compared with thin films (i.e., coatings of thickness typically of the order of $0.1 \mu \mathrm{m}$ ), thick films are attractive for their relatively low cost of processing. The specific applications of the conductive materials depend on the level of conductivity. For highly conductive materials of electrical resistivity of the order of $10^{-6} \Omega \mathrm{cm}$ (or below), applications include electrical interconnections and electrical contacts (such as brushes). For less conductive materials, applications include electrical grounding, lightning protection, resistance (Joule) heating and electrical resistance circuit elements. In the case of resistance heating, a high level of conductivity would require the use of a very long length of the conductor (such as a coiled wire or a thick film with a tortuous pattern) in order to attain the substantial resistance that is needed to provide sufficient heat $\left(I^{2} R\right)$ output. As a result, a moderate level of conductivity is desirable for resistive heating.

Thick films are made by the application of a paste onto a substrate. Depending on the composition of

(Received July 19, 2005; accepted August 12, 2005;

published online July 18, 2007) the paste, various degrees of heating may be needed after paste application in order to attain a film of sufficient conductivity and stability. The paste comprises a conductive component (such as metal particles) and a binder.

Binders that have been used include glasses (which undergo viscous flow at an elevated temperature) and polymers (which become viscous, melt or cure at an elevated temperature). ${ }^{1}$ However, these binders suffer from their being non-conductive. Owing to the insulating nature of the binder, percolation (i.e., attaining a continuous electrical conduction path through the touching of adjacent conductive particles) is essential for the composite to be conductive; without percolation, the composite remains non-conductive. The conductive component is commonly silver, due to its high conductivity. Silver is an expensive material. Thus, the use of a nonconductive binder tends to be associated with the need for a high volume fraction of the conductive component, and, consequently, high cost. A high volume fraction of the conductive component also means a low volume fraction of the binder, which results in less mechanical integrity in the thick film. Therefore, it is attractive from electrical, mechanical and cost points of view to use a conductive binder.

This paper describes thick films that involve a conductive binder, though the binder is not as conductive as the conductive component (namely silver). The binder is carbon, which is conductive, with a conductivity that increases with the temperature used to prepare the carbon from its precursor. One of the most common precursors is pitch. There are 
various types of pitch. Mesophase pitch is a type which is characterized by a high tendency to form graphite upon heating. This high tendency to crystallize stems from the liquid crystalline structure of mesophase pitch. Carbon is conductive. whereas pitch (a polymer mixture) is not. However, carbon is not an adhesive, whereas pitch is, due to its ability to flow. Therefore, this work used pitch as the binder precursor, which was a component of the thick film paste. However, carbon was the binder in the resulting thick film. In this way, this work provided silver particle carbon-matrix composites in the form of thick films. Prior work on silver particle carbonmatrix composites is limited to composites in a monolithic form. ${ }^{2}$

Metal particle carbon-matrix composites involving silver, ${ }^{3}$ iron, ${ }^{4}$ nickel, ${ }^{4}$ copper, ${ }^{4}$ and other particles have been previously reported in relation to applications including sliding electrical contacts. ${ }^{3,4}$ However, metal particle carbon-matrix composites have not been previously reported for thick film conductor applications.

The carbon-based thick films in this work are to be distinguished from carbon thin films that are made by pyrolysis of organic compounds ${ }^{5-11}$ or by chemical vapor deposition. ${ }^{12,13}$ The carbon-based films in this work are also to be distinguished from polymer-based films that contain carbon or graphite particles. ${ }^{14-20}$

The preparation of carbon from pitch is a process that has been studied extensively. ${ }^{21}$ This process involves stabilization (which is an oxidation treatment that is needed for avoiding melting and partial volatilization of the pitch during heating), followed by carbonization (which is the conversion to carbon). Graphitization is a further subsequent step that is needed, to provide crystallinity, which is associated with high electrical conductivity. Owing to the stabilization step, the process of conversion of pitch to carbon typically does not involve viscous flow. This is in contrast to the viscous flow of the glass binder during the firing of a thick film paste with a glass binder.

The temperature is low for stabilization (e.g., $350^{\circ} \mathrm{C}$ ); the temperature is higher for carbonization (e.g., $1,000^{\circ} \mathrm{C}$ ); the temperature is even higher for graphitization (e.g., $2,700^{\circ} \mathrm{C}$ ). Owing to the high temperature, graphitization is expensive and may not be feasible, due to the limited temperature resistance of the substrate (e.g., alumina) of the thick film. Therefore, graphitization was not included in the process used in this work. Further, the heat treatment temperature used in the carbonization step in this work was relatively low (e.g., $650^{\circ} \mathrm{C}$ ), due to the need to minimize volatilization of the resulting carbon. The volatilization is due to the reaction of carbon with oxygen to form gases such as $\mathrm{CO}_{2}$. It tends to occur to a certain extent even during purging by nitrogen, due to the tendency for imperfect purging. It is more detrimental to thick films than monolithic materials, due to the geometry.

The objectives of this work were (I) the development of conductive thick films involving a conduc-
Table I. Properties of Pitch

\begin{tabular}{lcc}
\hline Property & Description \\
\cline { 1 - 1 } Appearance & & Pellets (black) at \\
& $77^{\circ} \mathrm{F}\left(25^{\circ} \mathrm{C}\right)$ \\
Particle Size & $14 \mu \mathrm{m}$ \\
Specific Gravity & 1.23 at $77^{\circ} \mathrm{F}\left(25^{\circ} \mathrm{C}\right)$ \\
Vapor Pressure (mm Hg) & Nil \\
Initial Boiling Point & Decomposes \\
Solubility in Water & Insoluble \\
Bulk Density & $0.7 \pm 0.3 \mathrm{~g} / \mathrm{cm}^{3}$ \\
Glass Transition Temperature & $203^{\circ} \mathrm{C}$ \\
Softening Point & $285 \pm 5^{\circ} \mathrm{C}$ \\
\hline
\end{tabular}

Table II. Properties of Silver Particles

\section{Property}

Appearance

Particle Size

Specific Gravity

Vapor Pressure (mm Hg)

Solubility in Water

Boiling Point

Melting Point
Description

White metallic solid

$3 \mu \mathrm{m}$

10.49

$\mathrm{Nil}$

Insoluble

$2,200^{\circ} \mathrm{C}$

$966^{\circ} \mathrm{C}$ tive binder, (ii) the preparation and testing of silver particle carbon-matrix composites in the form of thick films, and (iii) the development of conductive thick films that exhibited a range of electrical conductivity, as needed for various applications.

\section{EXPERIMENTAL METHODS}

Mitsubishi Gas Chemical Company, Inc. (Japan) AR-grade mesophase pitch* was used as the binder precursor. The physical and chemical properties of this pitch are shown in Table I. This pitch is obtained by polymerization of naphthalene with a super-acid catalyst. It is characterized by a very low softening point and low viscosity at a molten stage while retaining a high coking value and $100 \%$ mesophase. The conductive component was silver particles produced by the Ames Goldsmith Corporation, with the properties shown in Table II. The liquid vehicle used in the paste was di(ethylene glycol) butyl ether (from Aldrich Chemical Co., Inc., Milwaukee, WI, USA). The weight ratio of ether to pitch ranged from 1:1 to $8: 1$; the higher the silver content, the greater was the proportion of ether. The volume fraction of silver was systematically varied from $8.1 \%$ to $69.3 \%$. The silver particles, pitch particles and ether were mixed manually with a glass rod to form a workable paste, which was then applied manually with a glass rod (followed by leveling of the top surface of the film with a razor blade) onto a $25 \mathrm{~mm} \times 5 \mathrm{~mm}$ region (defined by

\footnotetext{
*http://www.mgc-a.com/newProducts/media/ARBrochure.pdf
} 
masking the remaining part of the substrate by adhesive tape, which was removed immediately after paste application) of an alumina substrate ( $25 \mathrm{~mm} \times 25 \mathrm{~mm} \times 0.61 \mathrm{~mm}, 96 \% \mathrm{Al}_{2} \mathrm{O}_{3}, 3 \mathrm{M}$ Corp.).

The process of stabilization and carbonization used in this work is described below.

(a) Put the specimen in a box furnace and heat to $200^{\circ} \mathrm{C}$ in air at a heating rate of $1^{\circ} \mathrm{C} / \mathrm{min}$. This is the stabilization step.

(b) Remove the specimen from the furnace and allow the specimen to cool to room temperature.

(c) Put the specimen back into the furnace and purge the furnace chamber with nitrogen gas.

(d) Heat the furnace from $71^{\circ} \mathrm{C}$ to $200^{\circ} \mathrm{C}$ at $5^{\circ} \mathrm{C} / \mathrm{min}$, then from $200^{\circ} \mathrm{C}$ to $300^{\circ} \mathrm{C}$ at $2^{\circ} \mathrm{C} / \mathrm{min}$, and then from $300^{\circ} \mathrm{C}$ to $650^{\circ} \mathrm{C}$ at $4 \% \mathrm{~min}$. Finally, hold at $650^{\circ} \mathrm{C}$ for $30 \mathrm{~min}$ for the purpose of carbonization.

The stabilization temperature of $200^{\circ} \mathrm{C}$ was chosen because it is below the glass transition temperature of $203^{\circ} \mathrm{C}$ and the oxidation rate decreases sharply above the glass transition temperature. ${ }^{22}$

The DC sheet resistance and DC volume resistivity of the resulting thick films were measured by either the two-probe method or the four-probe method. The four-probe method involves four electrical contacts. The outer contacts are for passing current, whereas the inner contacts are for voltage measurement. In contrast, the two-probe method involves two electrical contacts, each of which is both for passing current and for voltage measure- ment. The four-probe method is more reliable, as the two-probe method includes the contact resistance in the measured resistance. However, in cases where the specimen resistance is large, the contact resistance is small compared to the specimen resistance, and the two-probe resistance result is reliable. In this work, the two-probe method was used only for specimens that exhibited very high resistance values $\left(10^{6} \Omega\right.$ or above), such as specimens that contained no silver.

Electrical contacts used for electrical resistance measurement were in the form of silver paint in conjunction with copper wires. Each contact was applied along the full width $(5 \mathrm{~mm})$ of the thick film strip. The thick film strip painted on the $1 \times 1$ in. $(25 \mathrm{~mm} \times 25$ $\mathrm{mm}$ ) alumina substrate was $5 \mathrm{~mm}$ in width and $1 \mathrm{in}$. $(25 \mathrm{~mm})$ in length. In the case of the four-probe method, the outer contacts were $20 \mathrm{~mm}$ apart and the inner contacts were $10 \mathrm{~mm}$ apart. In the two-probe method, the contacts were $15 \mathrm{~mm}$ apart.

We obtained the sheet resistance by dividing the measured resistance by the ratio of the distance between the inner contacts to the width of the thick film strip. The volume resistivity $\rho$ was obtained from the equation

$$
\rho=R \frac{w t}{\ell}
$$

where $w$ is the width, $t$ is the thickness, $\lambda$ is the distance between the voltage contacts, and $R$ is the

Table III. Sheet Resistance, Volume Resistivity and Thickness of Carbon-Matrix Thick Films with Various Silver Volume Fractions

\begin{tabular}{|c|c|c|c|c|}
\hline Silver volume fraction & Resistance $(\Omega)$ & Volume Resistivity $(\Omega \mathrm{cm})$ & Sheet Resistance ( $\Omega /$ sq.) & Thickness $(\mu \mathrm{m})$ \\
\hline \multirow[t]{2}{*}{$0^{*}$} & $58 \times 10^{6}$ & $(8.1 \pm 7.3) \times 10^{4}$ & $(2.92 \pm 0.44) \times 10^{7}$ & $28 \pm 25$ \\
\hline & $35.5 \times 10^{6}$ & $(5.0 \pm 4.4) \times 10^{4}$ & $(1.78 \pm 0.27) \times 10^{7}$ & $28 \pm 25$ \\
\hline \multirow[t]{2}{*}{$8.13 \% *$} & $2.27 \times 10^{6}$ & $(1.7 \pm 0.2) \times 10^{4}$ & $(7.60 \pm 1.00) \times 10^{5}$ & $229 \pm 25$ \\
\hline & $2.66 \times 10^{6}$ & $(1.4 \pm 0.2) \times 10^{4}$ & $(8.91 \pm 1.18) \times 10^{5}$ & $152 \pm 25$ \\
\hline \multirow[t]{2}{*}{$10.0 \% *$} & $2.30 \times 10^{6}$ & $(2.1 \pm 0.3) \times 10^{4}$ & $(1.16 \pm 0.17) \times 10^{6}$ & $178 \pm 25$ \\
\hline & $1.64 \times 10^{6}$ & $(1.9 \pm 0.2) \times 10^{4}$ & $(8.26 \pm 1.23) \times 10^{5}$ & $229 \pm 25$ \\
\hline \multirow[t]{2}{*}{$12.5 \% \dagger$} & 5.620 & $(3.2 \pm 0.7) \times 10^{-2}$ & $2.83 \pm 0.42$ & $114 \pm 25$ \\
\hline & 1.417 & $(7.2 \pm 1.8) \times 10^{-3}$ & $0.71 \pm 0.11$ & $102 \pm 25$ \\
\hline \multirow[t]{2}{*}{$15.0 \%^{\dagger}$} & 0.810 & $(6.2 \pm 1.0) \times 10^{-3}$ & $0.41 \pm 0.06$ & $152 \pm 25$ \\
\hline & 1.253 & $(8.0 \pm 1.6) \times 10^{-3}$ & $0.63 \pm 0.09$ & $127 \pm 25$ \\
\hline \multirow[t]{2}{*}{$20.9 \%^{\dagger}$} & 0.0661 & $(4.2 \pm 0.8) \times 10^{-4}$ & $(3.33 \pm 0.50) \times 10^{-2}$ & $127 \pm 25$ \\
\hline & 0.0678 & $(3.4 \pm 0.8) \times 10^{-4}$ & $(3.42 \pm 0.51) \times 10^{-2}$ & $102 \pm 25$ \\
\hline \multirow[t]{2}{*}{$30.0 \%{ }^{\dagger}$} & 0.0360 & $(3.4 \pm 0.5) \times 10^{-4}$ & $(1.81 \pm 0.27) \times 10^{-2}$ & $191 \pm 25$ \\
\hline & 0.0327 & $(1.9 \pm 0.4) \times 10^{-4}$ & $(1.65 \pm 0.25) \times 10^{-2}$ & $114 \pm 25$ \\
\hline \multirow[t]{2}{*}{$40.0 \%{ }^{\dagger}$} & 0.0134 & $(6.8 \pm 1.7) \times 10^{-5}$ & $(6.75 \pm 1.01) \times 10^{-3}$ & $102 \pm 25$ \\
\hline & 0.0119 & $(9.1 \pm 1.5) \times 10^{-5}$ & $(5.99 \pm 0.90) \times 10^{-3}$ & $152 \pm 25$ \\
\hline \multirow[t]{2}{*}{$50.0 \%{ }^{\dagger}$} & 0.00402 & $(3.8 \pm 0.5) \times 10^{-5}$ & $(2.03 \pm 0.30) \times 10^{-3}$ & $191 \pm 25$ \\
\hline & 0.00399 & $(3.0 \pm 0.5) \times 10^{-5}$ & $(2.01 \pm 0.30) \times 10^{-3}$ & $152 \pm 25$ \\
\hline \multirow[t]{2}{*}{$60.0 \%{ }^{\dagger}$} & 0.00669 & $(3.8 \pm 0.8) \times 10^{-5}$ & $(3.37 \pm 0.50) \times 10^{-3}$ & $114 \pm 25$ \\
\hline & 0.00774 & $(3.4 \pm 1.0) \times 10^{-5}$ & $(3.90 \pm 0.59) \times 10^{-3}$ & $89 \pm 25$ \\
\hline \multirow[t]{2}{*}{$69.3 \%{ }^{\dagger}$} & 0.00478 & $(2.7 \pm 0.6) \times 10^{-5}$ & $(2.41 \pm 0.36) \times 10^{-3}$ & $114 \pm 25$ \\
\hline & 0.00373 & $(2.1 \pm 0.5) \times 10^{-5}$ & $(1.88 \pm 0.28) \times 10^{-3}$ & $114 \pm 25$ \\
\hline
\end{tabular}

*Two-probe method.

†'Four-probe method. 
measured resistance. The thickness was measured with a micrometer. Owing to the error in the thickness measurement, the sheet resistance is more accurate than the volume resistivity. The conductivity is the reciprocal of the volume resistivity. At least two specimens of each composition were tested.

\section{RESULTS AND DISCUSSION}

Table III and Figs. 1 and 2 show the electrical resistance results as a function of silver volume fraction. In the absence of silver, the volume resistivity was about $7 \times 10^{4} \Omega \mathrm{cm}$. In the presence of silver up to 10.0 vol\%, the volume resistivity remained high (around $2 \times 10^{4} \Omega \mathrm{cm}$ ). Between silver contents of 10.0 and 12.5 vol\%, the volume resistivity decreased by six orders of magnitude, due to percolation. Beyond a silver content of $12.5 \mathrm{vol} \%$, the volume resistivity continued to decrease, though less abruptly. The lowest resistivity attained was $2 \times 10^{-5} \Omega \mathrm{cm}$, the value for the highest silver content $(69.3 \mathrm{vol} \%)$ investigated. However, the resistivity was only slightly higher than this when the silver content was 40.0 vol\%. A similar trend was obtained for the variation of the sheet resistance with silver volume fraction, as shown in Fig. 1.
Reference 2 reported that the volume electrical conductivity of silver particle carbon-matrix composites in monolithic form was $10^{5} \Omega^{-1} \mathrm{~cm}^{-1}$ at a silver content of $40 \mathrm{vol} \%$. The value obtained in this work at the same silver content was $10^{4} \Omega^{-1} \mathrm{~cm}^{-1}$ (i.e., a resistivity of $8 \times 10^{-5} \Omega \mathrm{cm}$ ). Thus, the conductivity values for the monolithic and thick film forms are quite close at 40 vol\% silver. However, in the regime of low silver content (e.g., 8 vol\%) and the regime of high silver content (e.g., 60 vol\%), the conductivity in Ref. 2 is substantially higher than that of this work. This difference between Ref. 2 and this work is due to the difference in the shape of the curve of conductivity (log) as a function of silver volume fraction. In Ref. 2 the conductivity (log) increases linearly with the silver volume fraction, hence showing no percolation effect. In contrast, percolation is clearly observed in this work at 12 vol\% (Figs. 1 and 2).

The absence of percolation in Ref. 2, in contrast to the presence of percolation in this work, is probably due to the difference in processing method and raw materials between Ref. 2 and this work. However, details on the processing method and raw materials are not given in Ref. 2 .

In addition to the experimental data, Fig. 2 shows a calculated curve based on the general effective

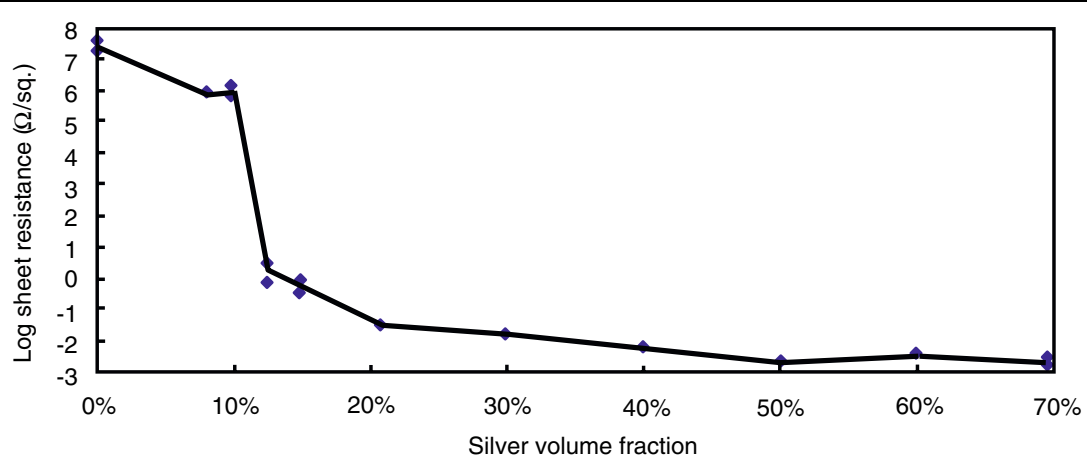

Fig. 1. Variation of the sheet resistance (log) with silver volume fraction.

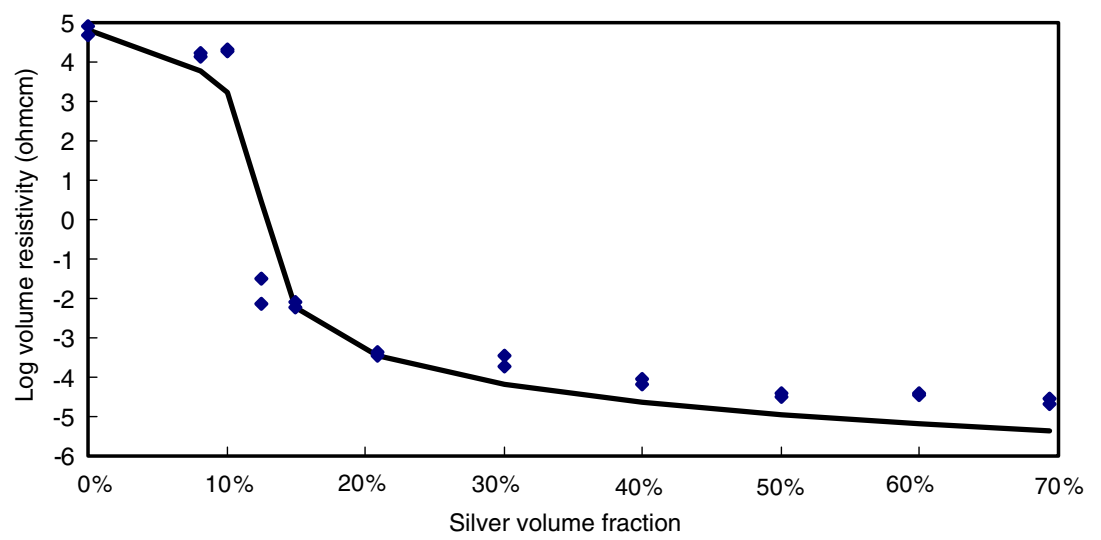

Fig. 2. Variation of the volume resistivity (log) with silver volume fraction. The data points are experimental. The curve is theoretical. 
media (GEM) model. ${ }^{23}$ The equation used to calculate the volume resistivity $\rho_{\mathrm{m}}$ of the composite is

$$
\frac{(1-\phi)\left(\rho_{\mathrm{m}}^{1 / t}-\rho_{\mathrm{h}}^{1 / t}\right)}{\rho_{\mathrm{m}}^{1 / t}+\left(\frac{1-\phi_{\mathrm{C}}}{\phi_{\mathrm{C}}}\right) \rho_{\mathrm{h}}^{1 / t}}+\frac{\phi\left(\rho_{\mathrm{m}}^{1 / t}-\rho_{\mathrm{l}}^{1 / t}\right)}{\rho_{\mathrm{m}}^{1 / t}+\left(\frac{1-\phi_{\mathrm{C}}}{\phi_{\mathrm{C}}}\right) \rho_{\mathrm{l}}^{1 / t}}=0,
$$

where $\rho_{\mathrm{h}}$ is the resistivity of the component with high resistivity, $\rho_{1}$ is the resistivity of the component with low resistivity, $\phi$ is the volume fraction of the component with low resistivity, $\phi_{\mathrm{C}}$ is the percolation threshold, which was found experimentally to be $12.5 \%$, and $t$ is the critical exponent, which was found by fitting to be 2.3 in this work. The calculated curve and the experimental data fit quite well, thus providing support for the occurrence of percolation in the composite system studied.

The calculated resistivity above the percolation threshold is lower than the experimental values, due to porosity, which was observed by scanning electron microscopy of the film surface. The pore size was typically around $5-10 \mu \mathrm{m}$.

The lowest resistivity attained in this work is $3 \times 10^{-5} \Omega \mathrm{cm}$, which is much lower than the value of $1 \times 10^{-3} \Omega \mathrm{cm}$ for silver paint. ${ }^{24}$ and silver epoxy. ${ }^{25}$ This is due to the conductive nature of carbon, compared to the nonconductive nature of epoxy or other organic vehicles. However, the value attained in this work is higher than the value of $4 \times 10^{-6} \Omega \mathrm{cm}$ for silver glass, ${ }^{1}$ in spite of the nonconductive nature of glass. This is because of the high temperature (e.g., $900^{\circ} \mathrm{C}^{1}$ ) associated with the firing of silver glass and the consequent sintering of the silver particles to form a network.

The silver volume fraction of the thick film composition (just above the percolation threshold of $12 \mathrm{vol} \%$ ) of this work was low compared to that of silver glass. Since silver is much more expensive than glass or pitch, a low silver volume fraction results in cost reduction.

The highest resistivity attained in this work was $8 \times 10^{4} \Omega \mathrm{cm}$ (for 0 vol\% silver). The second highest value is $2 \times 10^{4} \Omega \mathrm{cm}$ (for $8-10 \mathrm{vol} \%$ silver). Owing to the conductive nature of carbon, a silver content below the percolation threshold still causes the resistivity to decrease relative to the case without silver. These high values of the order of $10^{4} \Omega \mathrm{cm}$ are not provided by silver epoxy, silver paint, or silver glass. They are attractive for providing thick film resistors, which are needed for resistance heating, electrical circuits and other applications. The composition without silver is attractive also in that it gives films that are thinner $(30 \mu \mathrm{m})$ than those containing silver $(100-200 \mu \mathrm{m})$. The absence of silver makes the paste more workable, thereby resulting in a film that is thinner and more uniform.

\section{CONCLUSION}

Silver particle carbon-matrix composite thick films, along with their silver-pitch-ether paste precursor, were developed. The pitch (mesophase) was converted to carbon by heating in nitrogen at $650^{\circ} \mathrm{C}$ for $30 \mathrm{~min}$. This carbonization step was preceded by stabilization at $200^{\circ} \mathrm{C}$ in air. The resulting films on alumina were of thickness ranging from 90 to $230 \mu \mathrm{m}$, silver volume fraction ranging from $8 \%$ to $69 \%$, volume electrical resistivity ranging from $10^{-5}$ to $10^{4} \Omega \mathrm{cm}$, and sheet resistance ranging from $10^{-3}$ to $10^{6} \Omega /$ square. The percolation threshold was 12 vol\% silver, as shown by an abrupt drop in volume resistivity by seven orders of magnitude. The resistivity above the percolation threshold was above the calculated volume, due to porosity.

\section{REFERENCES}

1. Z. Liu and D.D.L. Chung, J. Electron. Mater. 33(3), 194 (2004).

2. I.R. McNab and J.L. Johnson, IEEE Transact. Components Hybrids Manufact. Technol. 1(1), 84 (1979).

3. C.-T. Lu and M.D. Bryant, IEEE Transact. Components Hybrids Manufact. Technol. Part A 17(1), 68 (1994).

4. S. Miyanaga, H. Yasuda, A. Hiwara, A. Nakumura, and H. Sakai, J. Macromol. Sci. Chem A27(9-11), 1347 (1990).

5. M. Fukuda and S. Mizogami, Patent No. JP 01131012, 5 pp (1989).

6. T. Akahira, S. Shimamune, and M. Tsuboyama, Rep. Sci. Res. Inst. (Jpn.) 28, 205 (1952).

7. S. Strijbos, Philips Res. Rep. 27(2), 186 (1972).

8. T. Endo, Patent No. JP 50095797, 3 pp (1975).

9. T. Ciborowski and K. Goratowski, Pol. Tech. Rev 9, 2 (1977).

10. J.T. Law, Patent No. GB 1246443, 5 pp (1971).

11. H. Ohdaira, H. Suzuki, and M. Saito, Int. J. Hybrid Microelectron. 6(1), 276 (1983).

12. K. Tezuka, S. Tateyama, and E. Sasaki, Patent No. JP 63289801, 4 pp (1988).

13. V.K. Dmitriev, V.N. Inkin, G.G. Kirpilenko, B.G. Potapov, E.A. Ilyichev, and E.Y. Shelukhin, Diamond Relat. Mater. 10(3-7), 1007 (2001).

14. I. Kaneko, A. Zaki, and C. Higuchi, Erekutoronikusu Jisso Gakkaishi 7(3), 230 (2004).

15. A.V. Kalmykov and P.A. Topolyanskii, Russ. J. Nondestruct. Test. 39(10), 757 (2003).

16. R. Modi, H.D. Wu, R.C.Y. Gilmore, and D.B. Chrisey, J. Mater. Res. 16(11), 3214 (2001).

17. M. Karaki, Patent No. JP 2001019891, 5 pp (2001).

18. K. Suga, Patent No. JP 08046315, 4 pp (1996).

19. H. Czarczynska, B. Licznerski, A. Dziedzic, A. Gasperowicz, and M. Wojcieszonek, Patent No. PL 168358, 3 pp (1996).

20. A. Dziedzic, H. Czarczynska, B.W. Licznerski, and I. Rangelov, J. Mater. Sci. 4(3), 233 (1993).

21. D.D.L. Chung, Carbon Fiber Composites (Butterworth-Heinemann, 1994).

22. Mitsubishi Gas Chemical Company, Inc., Impregnation and Stabilization Method for Carbon-Carbon Composites.

23. D.S. McLachlan, M. Blaszkiewicz, and R.E. Newnham, J. Am. Ceramic. Soc. 73(8), 2187 (1990).

24. C.-K. Leong and D.D.L. Chung, J. Electron. Mater 35(1), 118 (2006).

25. K.-D. Kim and D.D.L. Chung, J. Electron. Mater. 31(9), 933 (2002). 